\title{
Perceived Parenting Styles and Psycho-social Wellbeing of Nigerian Adolescents
}

\author{
${ }^{1}$ Ebernezer O Akinnawo, ${ }^{2}$ Bede C Akpunne*, ${ }^{3}$ Olufunmilayo A Olajide \\ ${ }^{1},{ }^{2}$ Department of Behavioural Studies, Faculty of Social Sciences, Redeemer's University, Ede, Osun State, \\ Nigeria. \\ ${ }^{3}$ Department of General Studies, Federal Polytechnic Ede, Osun State, Nigeria.
}

\begin{abstract}
The influence of parenting styles on the psychosocial wellbeing of Nigerian adolescents is yet to be given adequate research attention. This study bridges the gap in knowledge. Findings may be useful in planning appropriate interventions programme necessary to improve the psychosocial wellbeing of adolescents in Osun state, southwestern Nigeria and relation with similar social cultural background. Purposive sampling technique was used to select 332 (mean age $=14$ ) in-school adolescents who responded to Mental Health Continuum - Short Form (MHS-SF) and Parenting Style Instrument (PSI). Descriptive and inferential statistics (Regression, Independent sample t test and One Way ANOVA) were used for data analysis. A low level of psychosocial wellbeing was observed among the adolescents. Prevalence of very low levels of emotional wellbeing (16.9\%), social wellbeing (22\%), and psychological wellbeing (19.3\%) were reported. Patterns of observed parenting styles are authoritative parenting style $(45.5 \%, 41.6 \%$, and $12.9 \%)$, authoritarian parenting style $(53 \%, 30.7 \%$ and $16.3 \%)$; permissive parenting style $(64.2 \%, 20.7 \%$ and $15.1 \%)$ for low, high and very high levels respectively. No significant gender difference was observed in the psychosocial wellbeing scores of the adolescents; a significant religious affiliation difference was found in the social wellbeing of the participants. Adolescents from public schools manifested higher levels of social wellbeing than their counterparts from private schools. Parenting styles significantly predict level of psychosocial wellbeing of the adolescents. Neither family type nor family size had significant influence on level of psycho-social wellbeing of the adolescents.
\end{abstract}

Keywords: Parenting styles, psychosocial wellbeing, adolescents, Nigeria.

\section{Introduction}

Child rearing practice is a psychological concept representing standard strategies that parents use as their parenting style, which will influence psychosocial wellbeing of children especially adolescents. The most consistent predictor of adolescent psychosocial wellbeing is the quality of relationship adolescents have with their parents, (Resnick, Bearman, Blum, Bauman, Harris, Jones, \& Ireland, 1997). According to Ryff (1989), wellbeing model has six components; they are Self-Acceptance, Purpose in Life, Personal Growth, Positive Relation with Others, Environmental Mastery and Autonomy. Parents are key factors in the life of children, inversely, the child rearing practice engaged in by parents also affects the well-being of children and the consequences affect the society at large.

Parenting involves nurturing, instructing, directing, controlling and disciplining the children in preparation for their role in the society in general and personal life in particular. A child is born into a family setting and the family and whatever represents a home for the child is vital in the developing of the personality of the child. Face to face interaction within the family environment especially between parents and children molds the character and world view of the child and often influences social competence.

According to Salamone (2002) childrearing practice in Africa is a form of education, consisting of the development of the child's physical skills, development of character, respect for elders, development of 
intellectual skills and vocational training. It involves the development of the sense of belonging, active participation in the family and community affairs, and an effort to understand, appreciate and promote the cultural heritage of the community at large. It also include some forms of physical trainings carried out by emulating the adults performing the acts such as wrestling, boxing, climbing trees, music and dancing. Child rearing practice in Africa aims at the development of the character, requires the child to be sociable, honest, courageous, humble and preserving.

Baumrind (1980) categorized child rearing styles into three types: authoritarian, permissive and authoritative. Authoritarian parents are defined as rigid, punitive and demand unquestioning obedience from their children. They have very strict standards and discourage expressions of disagreement. Permissive parents are warm yet they require little from their children, hence they give their children law or inconsistent directions. Authoritative parents are firm, setting limits for their children. As the children get older, authoritative parents try to reason with and explain things to them. Negative parent-child relation results in the child's obsessive desire to please, deviance, lying, fearing closeness fearing risk, lack of confidence, hiding problems, escaping into a dream world, feeling of guilty and worthless and rebelliousness (Calafat, García, Juan, Becoña \& Fernández-Hermida, 2014). Negligent parenting style also erodes a child's selfconfidence, robs the child of emotional stability (Gómez-Ortiz, Del Rey, Romera, \& Ortega-Ruiz, 2015). The authoritative childrearing practice is democratic. It is described by Bertin (1992) as warm, characterized by openness and democratic pattern of handling matters affecting the parents and the child. Bakunin (2007) advocated for parenting styles that aim at developing a well-rounded individual.

Psychological wellbeing is a combination of having positive emotions, actively engaging in aspects of life, having good social relationships, finding meaning in life and a sense of accomplishment (Seligman 2011); it appears to have a strong correlation with a relatively new term that is currently emerging in literature. Psychosocial wellbeing is a term that does not have a globally recognized definition, however, it is perceived as a combination of cognitive, social, emotional and spiritual wellbeing. Cognitive wellbeing refers to values and having a rational and constructive approach to life's challenges. Social wellbeing refers to interactions with others in the sense of having good social support (support network) and an ability to adapt to various situations. Emotional wellbeing refers to an ability to accept and express various emotions (positive and negative). Spiritual wellbeing refers to one's life having a purpose or meaning and to a sense of belonging or connection with oneself, other people, nature or a higher power (Zinger 2016).

The term psychosocial well-being is from psychological well-being (PWB) connotes a wide range of meanings, usually associated with wellness. Most studies in the past defined, 'wellness' as not being sick, as an absence of anxiety, depression or other forms of mental problems. PWB includes esteem, positive effect, daily activities, satisfaction, absence of suicidal ideas, personal control, social support, absence of tension, and general efficiency (Bhogle \& Prakash, 1995). Ryff (1989) proposed well-being model with six components -Self acceptance, Purpose in life, Personal growth, Positive relation with others, Environmental mastery, Autonomy. Parenting style influences psychological well-being and personality of adolescents. The way parents bring up their children has an effect on children's behaviour (Lee, Daniels, \& Kissinger, 2006; Liem et al., 2010; Timpano et al., 2010).

According to Gupta and Mechtani (2015), child rearing patterns nurtures the child physically and contributes to overall well-being; an authoritative parenting style produced positive developmental outcomes. Similarly Cripps and Zyromsk, (2009) linked parenting style with a wide range of mental and psychological wellbeing and children of authoritative parents have been observed to achieve better personal, educational, social and emotional results (Jeynes 2007, Harris \& Goodall, 2008). In related study, Mehrnoush and Mohammadreza (2016) found that authoritative as well as permissive parenting styles were significant positive correlates of happiness among children while authoritarian parenting style negatively correlated with happiness among the Iranian adolescents.

Absence of either parents impacts on the style of childrearing in a family and could significantly influence behavior of children raised in such homes. For instance in an Austrian study on children aged 12 to 15 who were raised in fatherless families since infancy Golombok (1997) found that the behaviour of such children is not in conformity with societal expectations. Some of those children manifested delinquent behaviours while others were not generally happy with themselves. In an earlier study, Bowlby (1961) concluded that 
prolonged deprivation of the young child of maternal care may have grave and far reaching effects on his character and consequently on the side of his future life.

Several factors affect the psychosocial wellbeing of adolescents and parenting style is a very important significant factor. The family is the smallest unit in the society. Since parenting styles affect children, the implication of that effect is seen on the society at large. Children's earliest interactions occur within the family and can be positive or negative. For this reason, factors that affect early development in the family are probably the most crucial.

The influence of the family on the child and its roles in the emotional, social, and psychological wellbeing are very great and important. The interaction between children and parents and how parents communicate with children are considered very vital and fundamental in fostering and healthy behavior among children. To this end the focus of this present study include ascertaining patterns of psychosocial wellbeing among Nigerian children, determining the influence of gender and family size on levels of psychosocial wellbeing and finding out the predictive influence of perceived child rearing styles (authoritative, authoritarian and permissive) on psychosocial wellbeing of Nigerian children.

\section{Research Questions}

1. What are the patterns of psychosocial wellbeing and parenting styles of the sample?

2. What is the sex difference on psychosocial wellbeing of the adolescents?

3. Does family size significantly influence psychological wellbeing among the adolescents?

4. Is authoritative parenting style a significant predictor of psychosocial wellbeing?

5. To what extent is authoritarian parenting style a significant predictor of psychosocial wellbeing?

6. To what degree is permissive parenting style a significant predictor of psychosocial wellbeing?

\section{Research Hypotheses}

1. There will be significant gender difference on psychosocial wellbeing of the adolescents.

2. There will be a significant influence of family size on psychological wellbeing of the participants.

3. Authoritative parenting style will significantly predict psychosocial wellbeing among the adolescents.

4. Authoritarian parenting style will significantly predict psychosocial wellbeing of the participants.

5. Permissive parenting style will significantly predict psychosocial wellbeing of the participants.

\section{Materials and Method \\ Participants}

A cross sectional survey design was employed in the study. The population comprised of secondary school adolescents selected from five schools in Ede Osun state, Nigeria. A purposive sampling technique was adopted to select three hundred and thirty two respondents, who participated in the study.

\section{Research Instruments}

Two research instruments were used in data collection. To measure parenting styles the Parenting Style Questionnaire (PSQ) by Robinson, Mandleco, Olsen, and Hart, (1995) was used. It is a 30 item instrument, measured on a 6 points likert scale ranging from "never - always" PSQ has three sub scales (authoritarian parenting style, authoritative parenting style and permissive parenting style). It has acceptable psychometric properties for Nigerian samples.

For measuring Social Well-Being (SWB), Emotional Well-Being (EWB and Psychological Well-Being (EWB), the Mental Health Continuum-Short Form (MHC-SF) (Keyes et al., 2009) was used. The MHC-SF includes 14 items for assessing positive mental health (3 items to measure emotional well-being, 6 items for psychological well-being and 5 items for social well-being), with each item representing one dimension of the three components of well-being. The respondent rates the frequency of every feeling on a 6-point Likert scale $(0=$ never, $1=$ once or twice a month, $2=$ about once a week, $3=$ two or three times a week, $4=$ almost every day, 5=every day). The MHC-SF has a reliability value (Cronbach ${ }^{\text {ee }}$ alpha) of .89 (.74 for the social well-being scale, .83 for the emotional as well as the psychological well-being scale). MHC-SF has acceptable psychometric properties for Nigerian samples. 


\section{Data Analysis}

Collected data was analyzed using the Statistical Package of Social Sciences (SPSS). Descriptive statistic (frequency count and percentages) were used to organize, summarize and describe the demographic characteristics of respondents, while inferential statistic (independent sample t-Test, one way ANOVA and linear regression analysis) was employed to test the hypotheses.

\section{Results}

\section{Demographic Characteristics of Participants.}

A total of 332 adolescents were selected for this study. They were made up of 140 males and 192 females. The age distributions were between ages 9 to 19 years with mean age of 14 years. The distribution by father's occupation showed that 38\% (126) were civil servant, 50.3\% (167) were self-employed while $11.7 \%$ (39), artisan. Distributions by mothers' occupation returned the $31 \%$ (103) were civil servant; $64.8 \%$ (215) were self-employed while $4.2 \%$ (14) were artisan. $94.6 \%$ (314) of the respondents have mother in a marriage relationship, while, $5.4 \%$ (16) had mother as single parent. $74.4 \%$ (247) of the participants were from Monogamous family while $25.6 \%$ (84) were from polygamous homes. Participants caregivers was $81 . \%$ (268) stayed with both parents, $1.8 \%$ (6) lived with their fathers alone, 9.9\% (33) have mother as only caregiver, $3.9 \%$ (13) were in custody of some close relations who were not their parents and finally $3 \%$ (10) had guardians as caregivers.

Research Question 1: What are the patterns of psychosocial wellbeing and parenting styles of the sample?

\section{Table 1: Patterns of psychosocial well-being}

\begin{tabular}{|l|l|l|l|l|}
\hline & & & & N=332 \\
\hline & & Patterns (\%) & & \\
\hline & Very low & Low & High & Very high \\
\hline Emotional wellbeing & 16.9 & 33.1 & 49.4 & 0.6 \\
\hline Social wellbeing & 22 & 22.3 & 27 & 18.7 \\
\hline Psychological wellbeing & 19.3 & 25.3 & 54.8 & 0.6 \\
\hline Psychosocial wellbeing & 17.2 & 28.3 & 38.5 & 16 \\
\hline
\end{tabular}

Patterns of Psychosocial Wellbeing (PsW) summarized in Table 1 show that Emotional wellbeing range from $19.9 \%$ (very low level) to $0.6 \%$ (very high); Social Wellbeing range from $22.0 \%$ (very low level) to $18.7 \%$ (very high) range from $19.9 \%$ (very low level) to $0.6 \%$ very high Psychological wellbeing range from $19.3 \%$ (very low level) to $0.6 \%$ (very high level); finally Psychosocial wellbeing range from $17.2 \%$ (very low level) to $16.0 \%$ (very high level). Based on this it could be concluded that majority of the in-school adolescents in Ede community have low level of psychological wellbeing.

Table 2: Patterns of parenting styles

\begin{tabular}{|l|l|l|l|}
\hline & & & $\mathbf{N}=\mathbf{3 3 2}$ \\
\hline & & Patterns (\%) & \\
\hline Parenting style & Low & High & Very high \\
\hline Authoritative & 45.5 & 41.6 & 12.9 \\
\hline Authoritarian & 53 & 30.7 & 16.3 \\
\hline Permissive & 64.2 & 20.7 & 15.1 \\
\hline
\end{tabular}

$45.5 \%, 41.6 \%$, and $12.9 \%)$, authoritarian parenting style $(53 \%, 30.7 \%$ and $16.3 \%)$; permissive parenting style $(64.2 \%, 20.7 \%$ and $15.1 \%)$ for low, high and very high levels respectively.

Hypothesis one: There will be significant gender difference on psychosocial wellbeing of the adolescents. 
Table 3: Independent sample t-test of gender on domains and total psychosocial wellbeing

\begin{tabular}{|c|c|c|c|c|c|c|}
\hline & & & & & & $\mathrm{N}=332$ \\
\hline & Gender & $\mathbf{N}$ & Mean & SD & $\mathbf{t}$ & $p$ \\
\hline \multirow{2}{*}{ Emotional Wellbeing (EWB) } & male & 140 & 11.3 & 3.59 & \multirow{2}{*}{-1.658} & \multirow{2}{*}{0.098} \\
\hline & female & 192 & 11.94 & 3.35 & & \\
\hline \multirow{2}{*}{ Social Wellbeing (SWB) } & male & 140 & 17.46 & 6.34 & \multirow{2}{*}{-1.359} & \multirow{2}{*}{0.175} \\
\hline & female & 192 & 18.39 & 6.07 & & \\
\hline \multirow{2}{*}{ Psychological Wellbeing (PWB) } & male & 140 & 24.06 & 5.72 & \multirow{2}{*}{0.18} & \multirow{2}{*}{0.857} \\
\hline & female & 192 & 23.94 & 6.31 & & \\
\hline Psychosocial & male & 140 & 52.83 & 13.19 & \multirow{2}{*}{-0.984} & \multirow{2}{*}{0.326} \\
\hline Well Being & female & 192 & 54.28 & 13.28 & & \\
\hline
\end{tabular}

As shown in Table 3 an independent sample t- test was carried out to determine the influence of gender on the psychosocial wellbeing of the participants. The t-Test scores showed that there were 140 were male while and 192 were females. The mean $( \pm$ SD) on male and female showed emotional wellbeing scores $11.30 \pm 3.59$; and $11.94 \pm 3.35$; social wellbeing scores $17.46 \pm 6.34$ and 18.39 \pm 6.07 ; PWB $24.06 \pm 5.75$ and $23.94 \pm 6.31$ and Psychosocial Wellbeing (PsW) $52.83 \pm 13.19$ and $54.28 \pm 13.28$. The significant 2tailed $\mathrm{P}$ value associated with this test was .000 . The t-Test reveals no statistically significantly reliable difference between the means of the levels and total of psychosocial wellbeing scores of the gender difference. It could be concluded that the domains and total of psychosocial wellbeing of in school adolescents in Ede community is not a product of their gender.

Hypothesis two: There will be a significant influence of family size on psychological wellbeing of the participants.

Table 4: ONE Way ANOVA of family size influence on psychosocial wellbeing

\begin{tabular}{|l|l|l|l|l|l|}
\hline & & & & & $\mathbf{N}=332$ \\
\hline Family size & N & Mean & SD & F & $\boldsymbol{p}$ \\
\hline 1-3members & 20 & 53.8 & 13.2 & & \\
\hline 4-6 members & 178 & 53.81 & 13.12 & 0.011 & 0.989 \\
\hline 7 and above & 133 & 53.59 & 13.47 & & \\
\hline Total & 331 & 53.72 & 13.23 & & \\
\hline
\end{tabular}

A ONE Way Analysis of Variance (ANOVA) was carried out to determine the influence of family size on the psychosocial wellbeing of the participants. The ANOVA scores summarized in Table 4 showed that there were 20 were from $1-3$ family members, 4-6 family members while and 178, and 7 and above family members were 133 . The mean $( \pm \mathrm{SD})$ of psychosocial wellbeing scores were $53.80 \pm 13.20,53.81 \pm 13.81$ and $53.59 \pm 13.47$ respectively. The significant 2 -tailed $P$ value associated with this test was .000 . ANOVA reveals no statistically significantly reliable difference between the mean of the level of psychosocial wellbeing scores of the family size of the adolescents $\mathrm{F}(332)=.011, p=.989$. It can be therefore concluded that psychosocial wellbeing is not a product of family size.

Hypothesis three: Authoritative parenting styles will significantly predict psychosocial wellbeing among the adolescents

Table 5: Linear Regression Analysis of Authoritative Parenting Style on PsW

\begin{tabular}{|l|l|l|l|l|l|l|l|l|}
\hline & & & & & \multicolumn{3}{|c|}{$\mathbf{N = 3 3 2}$} \\
\hline & B & B & T & sig & $\mathbf{R}^{2}$ & F & $\boldsymbol{p}$ \\
\hline (constant) & 27.96 & & 6.35 & 0 & 0.096 & 34.93 & 0 \\
\hline Authoritative Parenting Style & 0.47 & 0.31 & 5.91 & 0 & & & \\
\hline
\end{tabular}


A linear regression analysis was conducted to determine whether authoritative parenting style independently and significantly predicted Psychosocial Wellbeing (PsW) among the participants. The result summarized in Table 5 revealed that authoritative parenting style independently and significantly predicted PsW among the participants $[F(1,331)=34.93, p=000]$. The analysis further reveals an $R^{2}$ of .096 indicating that $9.6 \%$ variance of PwB among the in-school children in Osun state Nigeria is influenced by authoritative parenting style.

Hypothesis four: Authoritarian parenting style will significantly predict psychosocial wellbeing of the participants.

\section{Table 6: Linear Regression Analysis of Authoritarian Parenting Style on PsW}

\begin{tabular}{|l|l|l|l|l|l|l|l|l|}
\hline & & & & & & \multicolumn{2}{|l|}{ N=332 } \\
\hline & B & B & T & sig & $\mathbf{R}^{\mathbf{2}}$ & F & $\boldsymbol{p}$ \\
\hline (constant) & 42.93 & & 15.41 & 0 & 0.046 & 15.9 & 0 \\
\hline Authoritarian Parenting Style & 0.25 & 0.214 & 3.99 & 0 & & & \\
\hline
\end{tabular}

A linear regression analysis was conducted to determine whether authoritarian parenting style independently and significantly predicted Psychosocial Wellbeing (PsW) among the participants. The result summarized in Table 6 revealed that authoritarian parenting style independently and significantly predicted PsW among the participants $[F(1,331)=15.90, p=000]$. The analysis further reveals an $R^{2}$ of .046 indicating that $4.6 \%$ variance of PsW among the in-school children in Osun state Nigeria is influenced by authoritarian parenting style.

Hypothesis five: Permissive parenting style will significantly predict psychosocial wellbeing of the participants

Table 7: Linear Regression Analysis of Permissive Parenting Style on PsW

\begin{tabular}{|l|l|l|l|l|l|l|l|l|}
\hline & & & & & & \multicolumn{2}{|l|}{$\mathbf{N 3 2}$} \\
\hline & B & B & T & Sig & $\mathbf{R}^{\mathbf{2}}$ & F & $\boldsymbol{p}$ \\
\hline (constant) & 55.34 & & 34.63 & 0 & 0.004 & 1.39 & 0.239 \\
\hline Permissive Parenting Style & -0.19 & -0.06 & -1.18 & 0.239 & & & \\
\hline
\end{tabular}

A linear regression analysis was conducted to determine whether permissive parenting independently and significantly predicted Psychosocial Wellbeing (PsW) among the in-school children in Osun state Nigeria. The result summarized in Table 7 revealed that permissive parenting style did not independently and significantly predicted PsW among the participants $[F(1,332)=1.39, p=.239]$. The analysis further reveals an $R^{2}$ of .004 indicating that $0.4 \%$ variance of PsW among the participants is influenced by permissive parenting style.

\section{Discussions}

The findings of this study on the patterns of patterns of PsW revealed high percent of low and very low emotional wellbeing, social wellbeing, psychological wellbeing and psychosocial wellbeing among the participants. This support previous research finding on high prevalence of poor mental health among Nigerians (Abiodun, 2006; WHO, 2006). In a study on the state of the Nigerian child, Atilola, Ayinde, Emedoh and Oladimeji (2014) reported that majority of Nigerian child related social and health indicators such as basic social indicators, health and nutrition, child education, maternal wellbeing and child protection were poor compared with Sub Saharan African average. With over $60 \%$ of Nigerian living below the poverty line of US\$1.25, (UNICEF 2012) and based on established link between poverty and poor mental wellbeing, (World Bank, 2001) meeting the social and emotional needs of children by parents may be hindered by poverty (Atilola 2012). Nigerian studies have also showed link between family poverty and activities that result in poor psychosocial health among children (Abdulmalik, Omigbodun, Beida \& Adedokun 2009; Atilola 2012). 
Furthermore this study found that the psychosocial wellbeing of male was similar to that of female students. This is supported by Savoye, Moreau, Brault, Leveque and Godin (2015) who reported that factors of wellbeing was similar between male and female adolescents. Research studies on gender differences in psychological well-being have yielded contradictory findings (Ryff \& Singer, 1998; Abbu-Rayya, 2005; Roothman et al., 2003). This is a pointer to the need to study more on the impact of gender on well-being outcomes. Previous studies showed that individual health complaints were more common among adolescent girls than boys (Saab \& Klinger, 2009; Wiklund, Malmgren-Olsson, Öhman, Bergström, Fjellman-Wiklund 2012).

In support of the research finding of Black, Devereux, and Salvanes (2005), the result of this study revealed that there is no significant difference in Psychosocial Wellbeing based on the family size. Research findings have shown the influence of family size and structure on the welfare of children (McHale, Updegraff, Jackson-Newsom, Tucker, \& Crouter, 2000, Stewart, 2005). Some researchers reported that the more children there are in a family the more likely will be competition for material resources and parental attention, and that in their parenting styles parents of large family's trade off quality for quantity (Becker \& Tomes, 1976). About $26 \%$ of the respondents of this study are from polygamous homes as well as other forms of complex family structures not identified in this study to this end, complex families often have more children than simple families, which imply that there would be more resource dilution. Distribution of family resources is thought to be more contentious in complex (large) families than in intact families (Cancian, Meyer, \& Cook, 2011). Also children not living with biological parents experience lower emotional and material investment from their non-biological caregivers as well as discrimination from biological children of caregivers with whom they dwell (Evenhouse \& Reilly, 2004) resulting in poor psychosocial wellbeing. According to McHale, et al, (2000) Children who receive less favorable parental treatment than their siblings are also more likely to have behavioral problems and internalizing symptoms.

Authoritative parenting style was found to be a significant independent predictor of PsW among the participants. This research finding is in agreement with most previous studies which found authoritative parenting as being associated with wellbeing and positive behavioural outcomes such as increased competence, autonomy, and self-esteem as well as better problem solving skills, better academic performance, more self-reliance, less deviance, and better peer relations (Akinsola, 2010,; Calafat, et.al 2014.; Gómez-Ortiz , Del Rey, Romera , \& Ortega-Ruiz, 2015). Children raised in environments that values and instills responsiveness and accountability as it is found in the authoritative parenting will, manifest balanced wellbeing. Authoritative parenting style brings about development of more positive psychological well-being, positive self-assessment, higher levels of self-esteem, adjustability, and happiness (Cripps \& Zyromski 2009; Eiser, Eiser, Mayhew, Gibson et al 2005).

This study found authoritarian parenting style to be a significant independent predictor of PsW among the participants. This finding is contrary to some previous studies which linked the authoritarian parenting style with negative behavioural outcomes including aggressive behaviour, decreased emotional functioning, depression and lower levels of self-confidence (Williams, 2013,; Olowodunoye \& Titus, 2011; Eiser et al 2005). The reason for this variation in finding could be as a result of differences in social-cultural settings in which the studies were carried out.

Permissive parenting style was not found to be a significant independent predictor of PsW among the participants. This research finding supports previous studies (Durbin, Darling, Steinberg, \& Brown, 1993; Miller, DiOrio, \& Dudley, 2002). The permissive parent indulges the child placing little or no demand on obedience to authorities, respect for self and others and shy away from confrontation with child on negative and maladaptive behaviours (Maccoby \& Martin, 1983). Again, permissive parenting has been positively correlated with delinquent and aggressive behaviour. Poor supervision, neglect, and indifference are characteristics of permissive parental practices, and this play crucial role in indirectly encouraging delinquency and poor psychosocial health among children. Studies have shown that adolescents from indulgent (permissive parenting) homes report a higher incidence of involvement in deviant behaviours, such as impulsivity, drug and alcohol use, emotional nonconforming behaviours and school misconduct (Durbin, et al 1993; Miller, DiOrio, \& Dudley, 2002), as well as difficulty in various areas of emotional development and have feelings of insecurity, (Olowodunoye \& Titus, 2011). 
Lack of involvement, as well as poor monitoring and supervision of children's activities, strongly predicts antisocial behaviour (Loeber \& Stouthamer-Loeber 1986). Permissive parenting style is linked with poor psychosocial wellbeing of children often manifesting as antisocial behavior and other psychopathological symptoms including drug use (Calafat, et.al 2014), inconsiderate and disrespectful treatment of parents, struggle with the interpersonal aspects of their emotional development and are emotionally dependent on others (Olowodunoye \& Titus, 2011). Such children exhibit poor self-esteem and depressive symptoms, (Engels, Finkenauer, Meeus, \& Deković, 2001), criminal behavior (Hoeve, Dubas, Gerris, Van der Laan \& Smeenk 2011), behavioral problems in school (Gracia \& Gracia, 2009) and bullying (Gómez-Ortiz et al, 2015), in adolescents.

\section{Conclusions}

The findings of present study show that high percentage of the participants fall within low and very low levels psychosocial wellbeing. Furthermore, authoritative parenting style as well as authoritarian parenting style is independent strong predictors of psychosocial wellbeing among the adolescents. Permissive parenting style is not a significant predictor of PsW among the in-school adolescents. Thus the psychosocial wellbeing of the Nigerian child is a product of parenting style.

\section{Recommendations}

Further studies that using the same methodology on a lager sample focused on preschool and in school children from other social cultural setting within Nigeria is recommended.

Conflicts of Interest: None declared.

\section{References}

[1] Abdulmalik J, Omigbodun O, Beida O, Adedokun B (2009) Psychoactive substance use among children in informal religious schools (almajiris) in northern Nigeria. Ment Health Relig Cult.; 12:527-42.

[2] Abiodun, OA. (2006) Postnatal depression in primary care populations in Nigeria. General Hospital Psychiatry, 28:133-136.

[3] Abu-Rayya HM (2005) Psychological traits of mixed-ethnic Arab-European adolescents in Israel. The Internet Journal of Mental Health.2,2

[4] Akinsola F (2010) Correlation between parenting styles and sexual attitudes of young people in Nigeria: Comparison of two ethnic groups. Gender and Behavior, 8(1), 2771 - 2788.

[5] Atilola O, (2012) Can family interventions be a strategy for curtailing delinquency and neglect in Nigeria? Evidence from adolescents in custodial care. Afr J Psychol Study Soc Issues.;15:218- 37

[6] Atilola O, Ayinde OO, Emedoh CT. Oladimeji O (2014) State of the Nigerian child - Neglect of child and adolescent mental health: A review. Annals of Tropical Paediatrics International Child Health 35(2):2046905514Y0000000137 DOI: 10.1179/2046905514Y.0000000137

[7] Baumrind D (1980) Current patterns of parental authority. Development Psychology Monographs, 4: $1-2$.

[8] Becker GS, Tomes N (1976) Child endowments and the quantity and quality of children. Journal of Political Economy, 84, S143- S162. https://doi.org/10.1086/260536

[9] Bertini CC (1992) Family and friends influence of the uptake of regular smoking form and adolescence to early childhood. Oxford: University Press.

[10] Bhogle S, Jay Prakash I (1995) Development of the psychological well-being questionnaire, Journal of Personality and Clinical studies, Vol. 11 (1 \& 2), pp. 5-9.

[11] Black SE, Devereux PJ, Salvanes KG (2005) The more the merrier? The effect of family size and birth order on children's education. The Quarterly Journal of Economics, 120, 669700. https://doi.org/10.1093/qje/120.2.669

[12] Bowlby OT (1961) Handbook of counselling psychology. New York: John Wiley and Sons.

[13] Calafat A, García F, Juan M, Becoña E, Fernández-Hermida JR. (2014) Which parenting style is more protective against adolescent substance use? Evidence within the European context. Drug Alcohol Depend; 138 185-192. 10.1016/j.drugalcdep.2014.02.705

[14] Cancian M, Meyer DR, Cook ST ( 2011) The evolution of family complexity from the perspective of non-marital children. Demography, 48, 957-982. https://doi.org/10.1007/s13524-011-0041-4 
[15] Cripps K, Zyromski B. (2009) Adolescents' psychological well-being and perceived parental involvement: Implications for parental involvement in middle schools. RMLE Online. Jan 1;33(4):13.

[16] Durbin DL, Darling N, Steinberg L, Brown BB. (1993) Parenting style and peer group membership among European-American adolescents. Journal of Research on Adolescents. 3(1), 87-100.

[17] Eiser C, Eiser JR, Mayhew AG, Gibson AT (2005) Parenting the premature infant: balancing vulnerability and quality of life. Journal of Child Psychology and Psychiatry. Nov 1;46(11):1169-77.

[18] Engels RC, Finkenauer C, Meeus W, Deković M. (2001) Parental attachment and adolescents' emotional adjustment: the associations with social skills and relational competence. Journal of Counseling Psychology; 48(4), 428-439.

[19] Evenhouse E, Reilly S (2004) A sibling study of stepchild well-being. The Journal of Human Resources, 39, 248-276. https://doi.org/10.2307/3559012

[20] García F, Gracia E. (2009) Is always authoritative the optimum parenting style? Evidence from Spanish families. Adolescence ; 44 101-131.

[21] Golombok SN (1997). Behaviour pattern in contemporary youth culture. Journal for Parent and Children 25(2)26

[22] Gómez-Ortiz O, Del Rey R, Romera EM, Ortega-Ruiz R. (2015) Maternal and paternal parenting styles in adolescence and its relationship with resilience, attachment and bullying involvement. An. Psicol. ; 31 979-989. 10.6018/analesps.31.3.180791

[23] Gupta DM, Mehtani D (2015) Parenting style and psychological wellbeing among adolescents: a theoretical perspective. Zenith International Journal of Multidisciplinary Research, 5(2), 74-84.

[24] Harris A, Goodall J (2008) Do parents know they matter? Engaging all parents in learning. Educational Research. Sep 1;50(3):277-89.

[25] Hoeve M, Dubas JS, Gerris JRM, Van der Laan PH, Smeenk W. (2011) Maternal and paternal parenting styles: unique and combined links to adolescent and early adult.

[26] Jeynes WH (2007) The relationship between parental involvement and urban secondary school student academic achievement a meta-analysis. Urban education. Jan 1;42(1):82-110.

[27] Keyes CLM (2009) Atlanta: Brief description of the mental health continuum short form (MHC-SF). Available: http://www.sociology.emory.edu/ckeyes/. (retrieved February 2019)

[28] Lee SM, Daniels H Kissinger DB (2006) Parental influences on adolescent adjustment: parenting styles versus parenting practices. The Family Journal, 14, 253. doi: 10. 1177/1066480706287654

[29] Liem JH, Cavell EC Lustig K (2010) The influence of authoritative parenting during adolescence on depressive symptoms in young adulthood: Examining the mediating roles of self-development and peer support. The Journal of Genetic Psychology, 171, 73-92.

[30] Loeber R, Stouthamer-Loeber M (1986) Family factors as correlates and predictors of juvenile conduct problems and delinquency. In M. Tonry, \& N. Morris (Eds.), Crime and justice (pp. 29-149). Chicago, IL: University of Chicago Press.

[31] MacCoby EE, Martin JA. (1983) Socialization in the context of the family: parent-child interaction, in Handbook of Child Psychology: Socialization, Personality and Social Development; Vol. 4. eds Hetherington EM, Mussen PH, editors. New York, NY: Wiley; 1-101

[32] McHale SM, Updegraff KA, Jackson-Newsom J, Tucker CJ, Crouter AC (2000). When does parents' differential treatment have negative implications for siblings? Social Development, 9, 149172. https://doi.org/10.1111/1467-9507.00117

[33] Mehrnoush M, Mohammadreza (2016). The Relationship between Parenting Styles and Happiness with the Mediating Role of Emotional Intelligence Int J Med Res Health Sci. 2016, 5(9S):667-673

[34] Miller JM, DiOrio C, Dudley W (2002) Parenting style and adolescent's reaction to conflict: Is there a relationship. Journal of Adolescent Health,; 31(6), 463-468.

[35] Olowodunoye S, Titus O. (2011) Parenting styles, gender, religiosity and examination malpractices. Gender \& Behavior, 9(2), 3941-3960. 
[36] Resnick MD, Bearman PS, Blum RW, Bauman KE, Harris KH, Jones J, Tabor J, Beuhring T, Sieving RE, Shew M, Ireland M, Bearinger LH, Udry JR (1997). Protecting adolescents from harm. Findings from the National Longitudinal Study on Adolescent Health. Jama, 278(10), 823-832

[37] Robinson CC, Mandleco B, Olsen SF, Hart CH. (1995) The parenting styles and dimensions questionnaire. In B.F. Perlmutter, J. Touliatos, \& G.W. Holden (Eds.). Handbook of family measurement techniques. Instruments and Index Thousand Oaks, CA: Sage.;3:319- 321).

[38] Ryff CD (1989) Happiness is everything, or is it? Explorations on the meaning of psychological well-being. Journal of personality and social psychology, 57(6), 1069.

[39] Ryff CD, Singer B (1998). The contours of positive human health. Psychological Inquiry, 9, 1-28. Santiago, C. (2008). Philippines: Country gender profile. Retrieved Oct. 18, 2011 from http://www.jica.go.jp/activities/issues/gender/pdf/j03phi.pdf

[40] Salamone FA (2002) Iwa and Kirki- Yoruba and Hausa child rearing compared _ Anthropological retrieved

https://www.academia.edu/33987021/Iwa and Kirki Yoruba and Hausa Child Rearing Compare d_Anthropologica.doc

[41] Saab H, Klinger D. (2010) School differences in adolescent health and wellbeing: Findings from the Canadian Health Behaviour in School-aged Children Study. Soc Sci Med. ;70(6):850-8. doi: 10.1016/j.socscimed.2009.11.012.

[42] Savoye I, Moreau N, Brault M, Leveque A, Godin I (2015) Well-being, gender, and psychological health in school-aged children. Arch Public Health. 73:52 doi: 10.1186/s13690-015-0104-X

[43] Seligman MEP (2011) Flourish A Visionary New Understanding of Happiness and Well-Being. Free Press, New York.

[44] Timpano KR, Keough ME, Mahaffey B., Schmidt NB, Abramowitz J (2010). Parenting and obsessive compulsive symptoms: Implications of authoritarian parenting. Journal of Cognitive Psychotherapy: An International Quarterly, 24(3), 151-164. doi: 10. 1891/0889-8391.24.3.151

[45] United Nations International Children Emergency Fund (UNICEF) (2012) Global study on child poverty and disparity. National report Nigeria. Retrieved January 2020 from https://www.unicef.org/socialpolicy/files/Nigeria GLOBAL STUDY ON CHILD POVERTY AN D_DISPARITIES_smaller.pdf

[46] WHO (2006). Neurological disorders: public health challenges. Geneva.

[47] World Bank (2001). World development report 2000/2001 — Attacking poverty. New York: Oxford University Press for the World Bank.

[48] Wiklund M, Malmgren-Olsson EB, Öhman A, Bergström, E, Fjellman-Wiklund A (2012). Subjective health complaints in older adolescents are related to perceived stress, anxiety and gender-a cross-sectional school study in Northern Sweden. BMC Public Health, 12, 1. doi:10.1186/1471-2458-12-993

[49] Williams L (2013) The 4 types of parenting styles. Retrieved from http://lqwilliams2.hubpages.com/hub/The-3-Types-of-Parenting-Styles. 2013.

[50] Zinger L (2016) psychosocial health, in RJ Donatele. Ed. Health: the basics Pearson education Inc. 